\title{
Commentary: Reconstructing Four Centuries of Temperature-Induced Coral Bleaching on the Great Barrier Reef
}

\author{
Thomas M. DeCarlo *t \\ Division of Biological and Environmental Science and Engineering, Red Sea Research Center, King Abdullah University of \\ Science and Technology, Thuwal, Saudi Arabia
}

Keywords: bleaching, false positive, type 1 error, climate change, coral

OPEN ACCESS

Edited by:

Stefano Goffredo,

University of Bologna, Italy

Reviewed by:

Hiroya Yamano,

National Institute for Environmental

Studies, Japan

Michelle Jillian Devlin,

Centre for Environment, Fisheries and

Aquaculture Science (CEFAS),

United Kingdom

Paolo Montagna,

Italian National Research Council, Italy

*Correspondence:

Thomas M. DeCarlo

tdecarlo@hpu.edu

tPresent address:

Thomas M. DeCarlo,

College of Natural and Computational Sciences, Hawai'i Pacific University,

Honolulu, HI, United States

Specialty section:

This article was submitted to

Coral Reef Research,

a section of the journal

Frontiers in Marine Science

Received: 12 May 2019

Accepted: 17 January 2020

Published: 29 October 2020

Citation:

DeCarlo TM (2020) Commentary:

Reconstructing Four Centuries of

Temperature-Induced Coral Bleaching

on the Great Barrier Reef.

Front. Mar. Sci. 7:30

doi: 10.3389/fmars.2020.00030

\section{A Commentary on}

Reconstructing Four Centuries of Temperature-Induced Coral Bleaching on the Great Barrier Reef

by Kamenos, N. A., and Hennige, S. J. (2018). Front. Mar. Sci. 5:283. doi: 10.3389/fmars.2018.00283

Mass coral bleaching events have occurred with increasing frequency over the past several decades (Hughes et al., 2018). It is generally thought that bleaching events either did not occur, or were exceedingly rare, prior to the 1980s (Glynn, 1993), which supports the attribution of recent bleaching events to increasing sea surface temperature (SST) associated with anthropogenic climate change (Hughes et al., 2017, 2018). Information preserved within the skeletons of long-lived corals is currently the only way to identify past bleaching events that were not directly observed by humans, and several studies have done so by detecting anomalous high-density "stress bands" (Carilli et al., 2009; Cantin and Lough, 2014; Barkley and Cohen, 2016; DeCarlo et al., 2017, 2019; Barkley et al., 2018; Mollica et al., 2019). A recent study (Kamenos and Hennige, 2018; hereafter "KH18") proclaimed a new bleaching proxy based on coral annual extension rates inferred from densitometer data made publicly available by the Australian Institute of Marine Science. KH18 presented provocative results, claiming to show that the Great Barrier Reef (GBR) of Australia has a long history of bleaching events dating back to the seventeenth century. According to KH18, widespread bleaching occurred in almost every decade since 1650 , with a total of 88 bleaching events over this time and as many as 6 bleaching events striking the GBR per decade during periods of the eighteenth and nineteenth centuries. If true, these results would completely re-write the history of coral bleaching on the GBR and would up-end several decades of scientific literature in coral reef ecology.

KH18 both misused the publicly available dataset and did not present any evidence that their theoretical bleaching proxy is accurate. In fact, KH18's own results clearly demonstrate the flaws in their method. Ignoring for now the improper use of the data (discussed in Hoegh-Guldberg et al., 2019), I tested the "validation" of their purported bleaching proxy, shown in Figure 3 of the original publication. Panel A shows a reasonably good correlation between "GBR bleaching prevalence (\%)" and "SST anomaly $\left({ }^{\circ} \mathrm{C}\right)$ ". Critically though, this panel does not show any kind of validation for two reasons: the data shown are the historical reconstruction (1700-1989) that extends far prior to direct observations, and a correlation between reconstructed bleaching and SST says nothing about the skill of the proxy in capturing real bleaching events. That the original article claims the correlation between SST anomaly and "reconstructed bleaching" is a validation of the proxy, and that the authors continue to make this claim in their Reply, demonstrates 

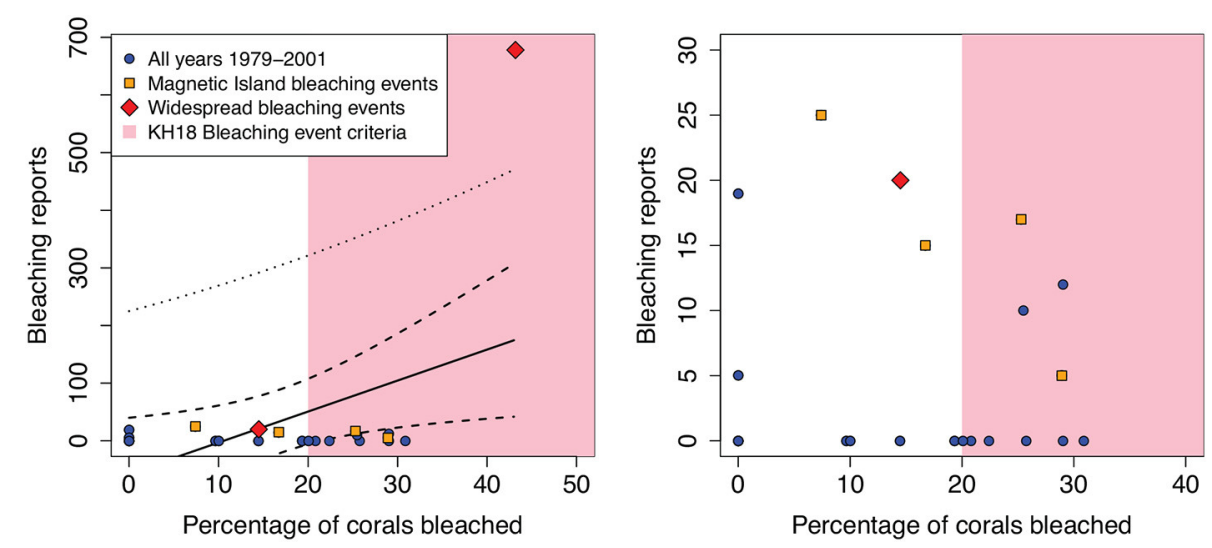

FIGURE 1 | Comparison of bleaching reports and KH18's proxy-based percentage of corals bleached, per year between 1979 and 2001 . The data were extracted directly from Figure 3 of $\mathrm{KH} 18$. Years with described bleaching events, both localized and widespread (see text for references), are shown with orange squares and red diamonds, respectively. The pink shaded background indicates KH18's $20 \%$ of corals bleached threshold for defining a widespread bleaching event. The best-fit line (solid black), standard error of the curve (dashed black), and standard error of prediction (dotted black) are shown for a regression between bleaching reports and percentage of bleaching corals. The right panel shows the same data, but zoomed in to show all years except 1998.

that they simply do not understand what it means to validate a proxy (in this case, comparing known bleaching events to reconstructed ones). Rather, the data that potentially could be used for validation are provided in Panels $\mathrm{Bi}$ and $\mathrm{Bii}$, which show number of reports (i.e., direct observations) of bleaching events and the proxy-based reconstruction of the percentage of bleached corals, respectively, during recent decades (19792001). Unfortunately, the data are only presented in separate bar charts, and it is only by comparing the two that KH18 could have made an attempt at validating their proxy. Here, I perform such a validation with two different approaches, but as described below, I find concerningly little skill in the KH18 methodology.

First, I plotted the number of bleaching reports against the proxy-based percentage of corals bleached, per year (Figure 1). I extracted these data directly from Figures 3Bi, Bii of KH18 using image analysis. A simple linear regression does show a significant positive relationship ( $p=0.025)$ between the two, as is expected from the purported bleaching proxy. However, this relationship is clearly driven entirely by a single year (1998) and we must ignore obvious statistical fallacies such as heteroskedasticity and structure in the residuals. Furthermore, despite the significance of the relationship, the uncertainties associated with the regression highlight the problems with KH18's proxy. According to their methodology, years in which more than $20 \%$ of corals "bleached" (as inferred from extension rates) were counted as widespread GBR bleaching events in the reconstruction. Yet, at $20 \%$ of "bleached" corals, the standard error of the regression line (dashed black line) ranges from -6 to 108 bleaching reports, and the standard error of prediction (dotted black line) ranges from -220 to 321 bleaching reports. In other words, the regression fit is so poor that at KH18's $20 \%$ threshold, there is not even enough skill to predict whether the number of bleaching reports would exceed 0 .

Nevertheless, it is well-known that numbers of bleaching reports may not be an effective measure of coral bleaching because they can be cofounded by reporting biases such as increases both in the number of observers and in awareness over time (Oliver et al., 2018). Therefore, as a second approach, I evaluated KH18's skill in capturing the presence/absence of directly observed bleaching on the GBR. Two years in the validation time period can reasonably be considered as widespread bleaching events: 1982 (Oliver, 1985) and 1998 (Berkelmans and Oliver, 1999). Since these two events do not provide a large testbed for the validation, I also included the locally observed events in 1980, 1987, 1992, and 1994 at Magnetic Island in the central GBR (Jones et al., 1997), which is the sector where the majority of the corals used by KH18 were collected. A contingency table of the predicted versus observed bleaching events is shown in Supplementary Table 1. I applied a variety of test statistics used in the evaluation of binary (presence/absence) event detection (Supplementary Table 2). These results demonstrate-resoundingly-that KH18's methods cannot be trusted. Their proxy has little accuracy above that of a coin toss, a strong bias in overpredicting bleaching events, a $73 \%$ probability of false alarms, a $47 \%$ probability of erroneously labeling each non-bleaching year as a bleaching event, and very little skill in accurately separating bleaching and nonbleaching years.

The most concerning aspect of KH18's approach is its high propensity for false positives. During just the 23 -year validation period, they erroneously predict eight widespread bleaching events during years in which bleaching did not occur. How, then, can we be expected to believe that KH18's reconstruction of 88 widespread bleaching events during 1650-1979 represents anything resembling reality? The $35 \%(8 / 23)$ rate of false positives during the validation period is similar to the upper limit of annual bleaching prevalence in their reconstruction post-1650, and it is consistent with the average of approximately 3 bleaching events per decade in the reconstruction. If we assume similar rates of false positives between 1650 and 1979, then effectively all of the "bleaching events" detected by KH18 disappear. In 
other words, their analysis fails to show, with any reasonable confidence, that a single widespread bleaching event occurred on the GBR prior to the 1980s. KH18 has already come under heavy criticism (Hoegh-Guldberg et al., 2019), based primarily on improper handling of SST data and errors in the analysis of the coral extension rates themselves. While these are critical issues, the absence of skill, and particularly the propensity for false positives, as demonstrated here falsifies the validity of any of KH18's results.

\section{REFERENCES}

Barkley, H., Cohen, A., Mollica, N., Brainard, R., Rivera, H., DeCarlo, T., et al. (2018). Repeat bleaching of a central Pacific coral reef over the past six decades (1960-2016). Commun. Biol. 1:177. doi: 10.1038/s42003-018-0183-7

Barkley, H. C., and Cohen, A. L. (2016). Skeletal records of communitylevel bleaching in Porites corals from Palau. Coral Reefs 35, 1407-1417. doi: 10.1007/s00338-016-1483-3

Berkelmans, R., and Oliver, J. K. (1999). Large-scale bleaching of corals on the Great Barrier Reef. Coral Reefs 18, 55-60. doi: 10.1007/s003380050154

Cantin, N. E., and Lough, J. M. (2014). Surviving coral bleaching events: Porites growth anomalies on the Great Barrier Reef. PLOS ONE 9:e88720. doi: 10.1371/journal.pone.0088720

Carilli, J. E., Norris, R. D., Black, B. A., Walsh, S. M., and McField, M. (2009). Local stressors reduce coral resilience to bleaching. PLoS ONE 4:e6324. doi: 10.1371/journal.pone.0006324

DeCarlo, T. M., Cohen, A. L., Wong, G. T. F., Davis, K. A., Lohmann, P., and Soong, K. (2017). Mass coral mortality under local amplification of $2^{\circ} \mathrm{C}$ ocean warming. Sci. Rep. 7:44586. doi: 10.1038/srep44586

DeCarlo, T. M., Harrison, H. B., Gajdzik, L., Alaguarda, D., Rodolfo-Metalpa, R., D'Olivo, J., et al. (2019). Acclimatization of massive reef-building corals to consecutive heatwaves. Proc. R. Soc. B Biol. Sci. 286:20190235. doi: $10.1098 /$ rspb.2019.0235

Glynn, P. W. (1993). Coral reef bleaching: ecological perspectives. Coral Reefs 12, 1-17. doi: 10.1007/BF00303779

Hoegh-Guldberg, O., Skirving, W. J., Lough, J. M., Liu, C., Mann, M. E., Donner, S., et al. (2019). Commentary: reconstructing four centuries of temperatureinduced coral bleaching on the Great Barrier Reef. Front. Mar. Sci. 6:86. doi: 10.3389/fmars.2019.00086

Hughes, T. P., Anderson, K. D., Connolly, S. R., Heron, S. F., Kerry, J. T., Lough, J. M., et al. (2018). Spatial and temporal patterns of mass bleaching of corals in the Anthropocene. Science 359, 80-83. doi: 10.1126/science.aan8048

\section{AUTHOR CONTRIBUTIONS}

TD conducted the analyses and wrote the manuscript.

\section{SUPPLEMENTARY MATERIAL}

The Supplementary Material for this article can be found online at: https://www.frontiersin.org/articles/10.3389/fmars. 2020.00030/full\#supplementary-material

Hughes, T. P., Kerry, J. T., Álvarez-Noriega, M., Álvarez-Romero, J. G. Anderson, K. D., Baird, A. H., et al. (2017). Global warming and recurrent mass bleaching of corals. Nature 543, 373-377. doi: 10.1038/nature 21707

Jones, R., Berkelmans, R., and Oliver, J. (1997). Recurrent bleaching of corals at Magnetic Island (Australia) relative to air and seawater temperature. Mar. Ecol. Prog. Ser. 158, 289-292. doi: 10.3354/meps158289

Kamenos, N. A., and Hennige, S. J. (2018). Reconstructing four centuries of temperature-induced coral bleaching on the Great Barrier Reef. Front. Mar. Sci. 5:283. doi: $10.3389 /$ fmars. 2018.00283

Mollica, N. R., Cohen, A. L., Alpert, A. E., Barkley, H. C., Brainard, R. E., Carilli, J. E., et al. (2019). Skeletal records of bleaching reveal different thermal thresholds of Pacific coral reef assemblages. Coral Reefs, 38, 743-757. doi: 10.1007/s00338-019-01803-x

Oliver, J. (1985). "Recurrent seasonal bleaching and mortality of corals on the Great Barrier Reef," in Proceedings of the Fifth International Coral Reef Congress (Tahiti).

Oliver, J. K., Berkelmans, R., and Eakin, C. M. (2018). "Coral Bleaching in Space and Time," in Coral Bleaching, eds M. J. H. van Oppen and J. M. Lough (Cham: Springer), 27-49. doi: 10.1007/978-3-319-753 93-5_3

Conflict of Interest: The author declares that the research was conducted in the absence of any commercial or financial relationships that could be construed as a potential conflict of interest.

Copyright (c) 2020 DeCarlo. This is an open-access article distributed under the terms of the Creative Commons Attribution License (CC BY). The use, distribution or reproduction in other forums is permitted, provided the original author(s) and the copyright owner(s) are credited and that the original publication in this journal is cited, in accordance with accepted academic practice. No use, distribution or reproduction is permitted which does not comply with these terms. 